\title{
Double high risk atrial fibrillation patient's
}

Submitted: 14 April 2016; Accepted: 15 April 2016; Published online: 19 April 2016

Atrial fibrillation is the most frequent arrhythmia which must be managed properly. As part of the evaluation and treatment, preventing embolism is a key in these patients. The two groups of drugs used to prevent embolism are oral anticoagulants and antiplatelets. The major secondary effect of both of these agents is bleeding, so a balance between preventing embolism and avoiding bleeding must be achieved. To make the correct decision scale $\mathrm{CHA}_{2} \mathrm{DS}_{2}$-VASc will help in the aid of embolism prevention and HASBLED scale will help in the bleeding evaluation. $\mathrm{CHA}_{2} \mathrm{DS}_{2}-\mathrm{VASc}$ punctuation equal or over 2 indicates necessity for oral anticoagulation and HASBLED equal or over 3 indicates a high risk of bleeding. The situation of high risk of embolism and high

\section{References}

1. Camm AJ, Lip GY, De Caterina R, et al. 2012 focused update of the ESC Guidelines for the management of atrial fibrillation: an update of the 2010 ESC Guidelines for the management of atrial fibrillation--developed with the special contribution of the European Heart Rhythm Association. Europace. 14, 1385-1413 (2012).

2. Warren JM, Daniel ES, Gregory YHL. Atrial fibrillation: Anticoagulant therapy to prevent embolization. Europace. 14, 1385-1413 (2012).

3. January CT, Wann LS, Alpert JS, et al. 2014 AHA/ACC/HRS Guideline for the Management of Patients With Atrial Fibrillation. A Report of the American College of Cardiology/American risk of bleeding is not infrequent and requires a correct management.

To give response to the question of what to do with patients with atrial fibrillation with a high risk of embolism and a high risk of bleeding, the main guidelines were reviewed: European Society of Cardiology [1], Up-todate [2], American College of Cardiology/ American Heart Association [3], National Institute for Health and Care Excellence (NICE) [4] and Cochrane Database [5,6]. The conclusions are that the new oral anticoagulants (apixaban, rivaroxaban and dabigatran) are the treatment of choice in these cases because the risk of bleeding of the new oral anticoagulants is lower when compared to warfarin and high risk of bleeding is not a reason for anticoagulant therapy exclusion.

Heart Association Task Force on Practice Guidelines and the Heart Rhythm Society. J. Am. Coll. Cardiol. 64, e1-e76 (2014).

4. NICE guidelines. Atrial fibrillation: management. (2014).

5. Bruins Slot KM, Berge E. Factor Xa inhibitors versus vitamin $\mathrm{K}$ antagonists for preventing cerebral or systemic embolism in patients with atrial fibrillation. Cochrane. Database. Syst. Rev. 8, CD008980 (2013).

6. Salazar CA, del Aguila D, Cordova EG. Direct thrombin inhibitors versus vitamin $\mathrm{K}$ antagonists for preventing cerebral or systemic embolism in people with non-valvular atrial fibrillation. Cochrane. Database. Syst. Rev. 3, CD009893 (2014).
Antonio L Aguilar-Shea*

Centro de Salud Puerta de Madrid, Spain *Author for correspondence: Tel.: +34918806699 antonio.aguilar@salud.madrid.org 